University of Nebraska - Lincoln

DigitalCommons@University of Nebraska - Lincoln

Faculty Publications: Department of

Entomology

Entomology, Department of

2000

\title{
Salinity and Shade Preferences Result in Ovipositional Differences between Sympatric Tiger Beetle Species
}

\author{
W. Wyatt Hoback \\ University of Nebraska-Lincoln, whoback@okstate.edu \\ Douglas A. Golick \\ University of Nebraska-Lincoln, dgolick2@unl.edu \\ Tina Marie Svatos \\ University of Nebraska-Lincoln \\ Stephen M. Spomer \\ University of Nebraska-Lincoln, sspomer1@unl.edu \\ Leon G. Higley \\ University of Nebraska-Lincoln, Ihigley1@unl.edu
}

Follow this and additional works at: https://digitalcommons.unl.edu/entomologyfacpub

Part of the Behavior and Ethology Commons, Biodiversity Commons, Entomology Commons, Other Ecology and Evolutionary Biology Commons, Terrestrial and Aquatic Ecology Commons, and the Zoology Commons

Hoback, W. Wyatt; Golick, Douglas A.; Svatos, Tina Marie; Spomer, Stephen M.; and Higley, Leon G., "Salinity and Shade Preferences Result in Ovipositional Differences between Sympatric Tiger Beetle Species" (2000). Faculty Publications: Department of Entomology. 349.

https://digitalcommons.unl.edu/entomologyfacpub/349

This Article is brought to you for free and open access by the Entomology, Department of at DigitalCommons@University of Nebraska - Lincoln. It has been accepted for inclusion in Faculty Publications: Department of Entomology by an authorized administrator of DigitalCommons@University of Nebraska - Lincoln. 


\title{
Salinity and Shade Preferences Result in Ovipositional Differences between Sympatric Tiger Beetle Species
}

\author{
W. Wyatt Hoback, Douglas A. Golick, Tina M. Svatos, Stephen M. Spomer, and Leon G. Higley \\ Department of Entomology, University of Nebraska-Lincoln, U.S.A.
}

\begin{abstract}
1. Adult tiger beetles of the genus Cicindela often co-occur within a habitat but larvae do not. Larvae are sedentary and form usually permanent burrows at the site of oviposition where they require 1-3 years for development.

2. To test niche partitioning based on ovipositional preference, the behavior of two sympatric salt marsh tiger beetles, Cicindela circumpicta and C. togata (Coleoptera: Cicindelidae), were examined.

3. In laboratory studies, female $C$. circumpicta and C. togata distinguished between experimental salinities, with the former preferring 4 parts per thousand (ppt) and the latter preferring $12 \mathrm{ppt}$. In the field, C. circumpicta larvae were associated with lower salinities (1-3 ppt) and vegetation along the edges of salt flats while $C$. togata larvae were found on open salt flats often near halophytes (average salinity $=7.8 \mathrm{ppt}$ ).

4. In the field, females chose sites for oviposition in response to shade but not vertical landmarks. In a direct test, 53 of 56 new larval burrows occurred in shaded treatments, three in nonshaded controls.

5. Compared with nonshaded controls, shade increased survival of eggs that were collected in the laboratory and placed in the field. For $C$. circumpicta eggs, $78 \%$ placed in shaded treatments hatched, while significantly fewer $(22 \%)$ hatched in exposed treatments. For C. togata, $43 \%$ of eggs placed in the shade hatched, while no eggs placed in exposed treatments hatched.

6. These results support the hypothesis of niche partitioning between C. circumpicta and C. togata based on ovipositional choice and resulting larval habitat.
\end{abstract}

Keywords: Cicindela circumpicta, Cicindela togata, Niche partitioning, Oviposition, Salinity, Salt flat

\section{Introduction}

The concept of niche is fundamental to understanding how organisms are distributed and is assumed to be exclusive to a species (Ricklefs, 1990). Closely related species that overlap broadly in habitat use, resource use, and activity pattern (niche) appear to defy the principle of competitive exclusion (Gause, 1934). Several examples of apparent niche cooccurrence by herbivores have been studied. For example, based on similarity in phenology, body size, and food preferences, Ross (1957) reported that six species of leafhoppers in the genus Erythroneura Fitch occupied the same niche. Similarly, Broadhead (1958) reported that two psocid species in the genus Mesopsocus Kolbe (Psocoptera) coexisted in larch plantations. In both cases, however, further detailed studies revealed important differences in niche use. The leafhoppers studied by Ross proved to differ geographically, such that their habitats did not overlap (McClure \& Price, 1976). The psocids studied by Broadhead differed in oviposition site (Broadhead \& Wapshere, 1966). The principle of competitive exclusion is a key issue in understanding

Correspondence: W. Wyatt Hoback, Department of Biology, Kearney, Nebraska, U.S.A.; hobackww@unk.edu speciation and it seems especially explanatory for highly diverse groups such as insects. Based on energy flow and resource availability, one prediction from the competitive exclusion principle is that niche specialisation should be pronounced among co-occurring predatory species. Specialisation in such species is therefore an important test of the power of the competitive exclusion principle. In particular, identifying details of how potentially competitive species have differentiated their life-history requirements provides insights into forces that drive and maintain species diversity. So far, there are few tests of niche differentiation for predatory insects.

Probably the best-studied insect predators that have large niche overlap are tiger beetles (Coleoptera: Cicindelidae) in the genus Cicindela L. (Pearson, 1988; Knisley \& Schultz, 1997). Adult Cicindela often form assemblages of two to 10 species that occur sympatrically. Some of these assemblages have been examined extensively for differences in timing of activity, microhabitat use, and prey use that result in niche partitioning (Pearson, 1988; Knisley \& Schultz, 1997), however assemblages of adults of many species, including those restricted to saline habitats, appear to have broad niche overlap (Willis, 1967; Schultz \& Hadley, 1987; Pearson 
\& Juliano, 1991; Knisley \& Schultz, 1997). As seen in the psocids mentioned previously (Broadhead \& Wapshere, 1966), a key factor in the continued coexistence of tiger beetle assemblages may be differences in oviposition site choice.

The importance of oviposition site choice for insects is widely recognised (Southwood, 1979; Price, 1997) and site choice may constitute the primary form of postfertilization investment in the majority of species. The eggs of predators must be placed in areas that are suitable for egg survival and that provide access to appropriate prey. Among predaceous insect species, oviposition site choice should be of greatest importance for species whose larvae remain at the site of egg hatching and have a prolonged developmental period.

Tiger beetles exemplify these criteria and are therefore model organisms for studies of oviposition preferences. Tiger beetle adults are active predators that mostly occur in open habitats such as seashores, riverbanks, and salt flats where they feed on a wide range of small organisms (Pearson, 1988). Tiger beetle larvae are also predaceous but differ from adults by being sitand-wait predators that construct narrow, usually permanent, burrows at the oviposition site. Larvae use the same burrow, enlarging it as they develop, in a process that requires 1-3 years or more depending on species, environmental conditions, and prey availability (Knisley, 1984, 1987).

Few studies have examined factors that contribute to tiger beetle oviposition choice (Criddle, 1907, 1910; Shelford, 1908, 1911; Schultz, 1989). Female oviposition preference for soil types and other habitat characteriztics has been observed or inferred based on larval distribution, but field tests have not been performed. Schultz (1989) found that larvae of eight sympatric Texas cicindelid species occurred in one of four specific soil types, but the mechanism for this partitioning was not determined. Other studies have reported that larvae of cooccurring species are segregated based on topography, vegetation cover, slope, soil type, soil particle size, and soil moisture level (Shelford, 1908; Willis, 1967; Knisley, 1987). Non-overlap of larval habitat may be evidence of niche partitioning for sympatric species, but the proximate mechanism for female oviposition has been investigated only in controlled laboratory studies of three species: Cicindela limbalis Klug, C. sexguttata Fabr., and C. tranquebarica Herbst (Shelford, 1908). These data do not demonstrate niche partitioning based on female choice because these species were not from populations that were sympatric as adults or larvae. In the work reported here, oviposition preferences of female Cicindela circumpicta LaFerte and C. togata LaFerte were compared in a series of laboratory and field manipulations. It was hypothesised that females would make choices based on soil salinity and soil shading and that preferences would differ between species resulting in observed niche partitioning of larval burrows.

Materials and Methods

Study Site

These studies were conducted on two salt flats within the Arbor Lake Wildlife Management Area (Nebraska, U.S.A.; $40.5^{\circ} \mathrm{N}, 96.7^{\circ} \mathrm{W}$ ), an area of protected eastern Nebraska salt marsh. The salt marshes formed in eastern Nebraska during the Cretaceous by the flow of ground waters through salt-rich Dakota sandstone. The sandstone deposits are overlain by glacial till and loess deposits. The ground waters carrying dissolved salts percolate through the loess soil layers and evaporate at the surface, leaving salt behind. Beneath the salt crust, the salt marsh soil is characterized by silty-clay loam, mixed, and has weak granular structure (U.S. Soil Conservation Service, 1980). The high concentration of salt restricts plant life to halophytes like salt grass Distichlis spicata (L.) Greene and saltwort Salicornia rubra A. Nels. These halophytes grow sparsely around the edges of the salt flat and are gradually replaced by nonsaline restricted species like brome grass Bromus spp. as the distances from salt deposits increase. Although water is seasonally abundant, the substrate becomes arid in the summer and surface temperatures of bare soil may exceed $60^{\circ} \mathrm{C}$ (Willis, 1967). The soil in the shade of plants is about $10^{\circ} \mathrm{C}$ cooler (see Results).

The remnant salt marshes provide habitat for a rich fauna of 10 tiger beetle species found in sympatry (Spomer et al., 1997). Tiger beetles are characterized, in part, by the life-history patterns of adults. Species that are active as adults once a year are known as summer species; those that emerge twice with an intervening period of diapause are called spring-fall species (Criddle, 1907). In the eastern Nebraska salt marsh, three species (C. fulgida Say, C. togata, and C. circumpicta) are restricted to exposed salt flats. Of these, C. fulgida is a springfall species and the others are summer species. The experiments in this study were restricted to the summer species to test for female behavior leading to niche partitioning for species that should be in direct competition.

\section{Background Field Data}

In 1997, the relationship between salt concentration and presence of tiger beetle larvae was tested by establishing a $3 \times 14 \mathrm{~m}$ rectangular transect on the salt flat. The transect was established by driving 3-cm wide, 30$\mathrm{cm}$ tall wooden lathes into the salt flat at $1 \mathrm{~m}$ intervals so that about $10 \mathrm{~cm}$ remained above the surface of the flat. Within each $1 \mathrm{~m}$ square, soil salinity was sampled 
randomly. To determine soil salinity, three $\approx 1 \mathrm{~g}$ plugs of soil were collected using a cork borer to sample to a depth of $1 \mathrm{~cm}$. Individual soil plugs were mixed with $50 \mathrm{ml}$ of de-ionized water to form a saturated solution, and a YSI model 30 hand-held salinity meter (Yellow Springs, Ohio) was used to measure salt concentration in parts per thousand (ppt). During measurements, soil surface temperatures and air temperatures were approximately $30^{\circ} \mathrm{C}$.

Within each transect, the surface was examined visually for burrows of active tiger beetle larvae. The number of first-, second-, and third-instar burrows were recorded, but larvae were not extracted and species were not determined. The transect remained in place throughout the study, and a relatively large number of first-instar burrows was observed in the shade of the transect, suggesting that tiger beetle females were using shade as an ovipositional signal, so a second field trial was implemented in 1998.

Willis (1967) reported microhabitat segregation of larval C. circumpicta and C. togata, with the former found in grassy areas near the edges of the salt flats and the latter found in exposed areas. As part of ongoing research on immersion survival (Hoback et al., 1998), a large number of tiger beetle larvae were collected from exposed salt flats. All larvae were later identified as $C$. togata. Subsequently, larvae were dug from grassy areas at the margin of the salt flat (salinity $\sim 1 \mathrm{ppt}$ ) and were identified as predominately $C$. circumpicta.

\section{Salinity Preferences}

Cicindela circumpicta and C. togata are restricted to saline soils (Willis, 1967) and it seemed reasonable that salt might be required to stimulate ovipositing behavior. Thus, the effect of salinity on female ovipositional preferences was compared in the laboratory. The test chambers consisted of 10-liter glass aquaria. The aquaria were lined with paper towel substrate and provided with a cotton-plugged water vial and four oviposition dishes. Oviposition dishes consisted of the bottom half of 5.5-cm diameter, 1.3-cm deep plastic Petri dishes. Dishes contained greenhouse soil that was modified by adding distilled water or one of three concentrations of salt. Salt concentrations of $0,4.0,8.6$, and $12.4 \mathrm{ppt}$, similar to the range of field salinities where larval burrows were observed, were used. Experimental salinities were created by adding $0,2.4,4.8$, or $7.2 \mathrm{~g}$ of salt respectively to 109 of sterilized greenhouse soil, then wetting the mixture with $600 \mathrm{ml}$ of distilled water. Salinities were checked using a YSI salinity meter each time eggs were collected and new oviposition dishes were established.

Fifteen adults (five males and 10 females) of two summer species, C. circumpicta and C. togata, were collected from Arbor Lake. In the laboratory, beetles were subdivided into two groups and placed in aquaria lit from above with a $60-\mathrm{W}$ incandescent light bulb. The bulb maintained chamber temperatures at about $30^{\circ} \mathrm{C}$. Beetles were fed ad libitum apterous Drosophila melanogaster Meigen. The oviposition dishes were checked for eggs approximately every other day until all adults died. Eggs from each treatment were removed from the dish, stored in moistened dirt, and subsequently used in the field experiment to examine the effect of shading on egg and early first-instar survival (see below).

\section{Effect of Shade/Vertical Stimulus on Oviposition}

For the 1998 field manipulation experiments, two small $(\approx 10 \times 20 \mathrm{~m})$ salt flats that were separated by areas of nonsaline soils covered with seasonal grasses were selected. Salt concentrations of these flats were between 6 and 9 ppt and declined to about I ppt near the edges. All experiments were conducted in the middle area of the flats. These salt flats had been submerged by spring rain to a depth of $0.3-0.5 \mathrm{~m}$ for approximately 1 week prior to the start of the field experiments. Twelve square wooden stakes $(2 \times 2 \times 30$ $\mathrm{cm}$ ) were placed in a randomly ordered series on the two salt flats, away from plants and existing tiger beetle burrows on June 28, 1998. The stakes were driven into the salt flat so that $10 \mathrm{~cm}$ remained above the flat surface. The area surrounding the stakes was checked at approximately weekly intervals and the number of new first-instar tiger beetle burrows was recorded. On August 19, the distance from the stake to each burrow was measured and assigned a compass direction (to the nearest $5^{\circ}$ ) for each burrow. The Rayleigh Test was performed to determine the main direction angle and to test whether burrows were oriented in relation to the stakes (Batschelet, 1981). The angles of the burrows were then combined by directional quadrat and tested for differences using a $\chi^{2}$ goodness-of-fit test. To test further the influence of shade on female oviposition preference, 18 wire frames $(8.5 \times 14 \mathrm{~cm})$ were placed at random on an exposed salt flat where tiger beetle burrows were absent. A piece of wire extended from the wire frame at a $90^{\circ}$ angle and held the frame approximately $6 \mathrm{~cm}$ above the surface of the salt flat. Nine of the frames were covered with a double layer of 2-mm nylon screen mesh and nine were left uncovered to serve as controls for vertical stimuli. The screen mesh provided constant shade to the area of soil beneath it, reducing the penetration of light by about 65\% (1950 umol photons $\mathrm{m}^{-2} \mathrm{~s}^{-1}$ in direct sun compared to 650 $\mu$ mol photons $m^{-2} s^{-1}$ under shade) as measured with a quantum sensor on a portable photosynthesis system (LiCor model LI-6200, Lincoln, Nebraska). The areas beneath the empty frames and the screened frames were checked approximately weekly and the number of first-instar burrows was determined. 


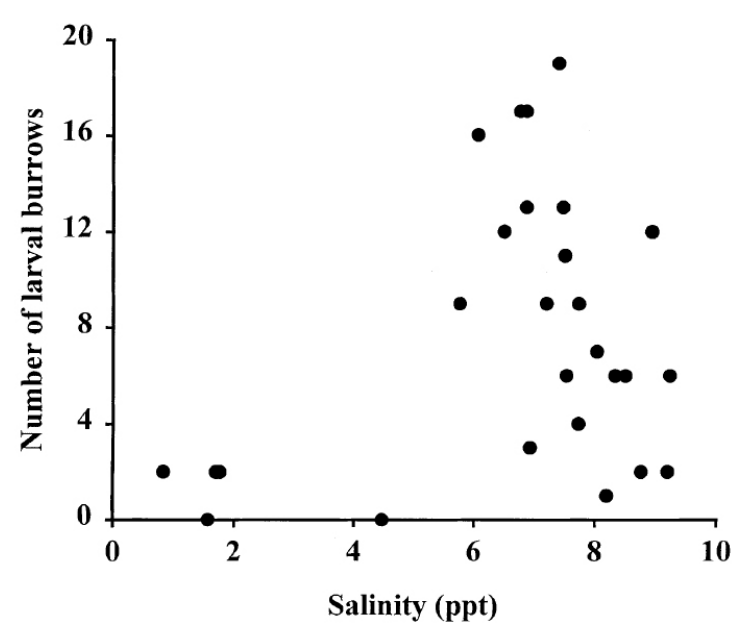

Figure 1. Number of tiger beetle burrows (all instars) in relation to salt concentration.

\section{Shading Effects on Larval Survival}

Because wild females used the presence of shade as an oviposition cue, the role of shade on egg and early instar survival was tested. Tiger beetle eggs from the laboratory experiment were transported to the field within 6 days of deposition and placed individually into 1-cm holes dug with a dissecting needle. Artificial oviposition holes were marked with numbered golf tees, and eggs were transferred using a camel hair brush. The holes were then covered with a small amount of soil. The eggs were placed into either shaded conditions (placement of previously described wire frames with screen) or exposed conditions (the absence of any structure) and were placed on exposed salt flats that had no pre-existing larval burrows. A total of 20 C. circumpicta and 14 C. togata eggs was tested, half in shade and half exposed. Eggs were placed in the field on June 29.

The possibility that the shade altered many attributes of the microhabitat simultaneously was considered. Consequently, in addition to a reduction of penetrating light, soil surface temperature during the experiment and soil salinity after $\approx 1$ month of the experiment were measured. The surface temperature on exposed areas of the salt flat, in the shade of plants, and beneath the artificial shade was measured using a high-performance infrared thermometer (Raytek model Raynger MX4, Santa Cruz, California). Soil salinity was measured as described previously from five exposed areas and five controls by taking one soil sample from beneath the shade and one from immediately adjacent to the shading structure.
Results

Initial Field Data

Within transects, no correlation between salt concentration and the number of larval burrows was found (Figure 1). During both summers of the study, salt concentrations were between 6 and 9 ppt and declined to about 1 ppt near the edges of the salt flat where halophytes were replaced by other grasses. During sampling, the majority of burrows was found in the shade of halophytes growing on the exposed areas of the salt flat. For this experiment, the species of larval tiger beetle was not differentiated, however in subsequent sampling $C$. togata larvae were found primarily on open flats (salinity $>6.0 \mathrm{ppt}$ ), with occasional larvae found near the edges, whereas $C$. circumpicta occurred exclusively at the edges where salinities were lower " $5.0 \mathrm{ppt}$ ).

\section{Salinity Preferences}

From the field data, it appears that summer salt marsh tiger beetles use salinity as an important oviposition stimulus. In laboratory trials, significant speciesspecific preferences for soils of different salinity were found (Figure 2). Female C. circumpicta oviposited almost exclusively in soil with a salinity of $4.0 \mathrm{ppt}(28$ eggs in $4.0 \mathrm{ppt}$, one egg in 8.0 ppt treatment; $\chi^{2}$ test $P$ $<0.001$ ). Female $C$. togata laid increasing numbers of eggs as treatment salinity increased, with the majority of eggs (11 of 19) being placed in the 12.0 ppt treatment (Figure 2). Salt appeared to be a requirement for oviposition because neither species oviposited in the control greenhouse soil without salt.

\section{Effects of Shade/Vertical Stimulus on Oviposition}

While collecting background data, a number of new firstinstar burrows near the transect stakes was noted; the role of vertical stimuli and shade on female oviposition in 1998 was tested. A total of 75 new tiger beetle larvae was found within $15 \mathrm{~cm}$ of the stakes (Figure $3 a)$. Significantly more new larval burrows $(63 \%)$ were found between 0 and $5 \mathrm{~cm}$ from the stakes, while $26 \%$ of new burrows occurred between 5 and $10 \mathrm{~cm}$, and $11 \%$ were between 10 and $15 \mathrm{~cm}$ from the stakes $\left(\chi^{2}\right.$ goodness of fit, $P<0.01$; Figure 3a). These data suggest that females were using either shade or vertical stimuli as oviposition cues. The orientation of the burrows in relation to the stakes was examined to address whether oviposition was occurring during a specific time of day, reasoning that the stakes would act like a sundial and cast shadows at predictable angles. The orientation of the burrows from the stakes was random (Rayleigh statistic for angles of all burrows; $P>$ 


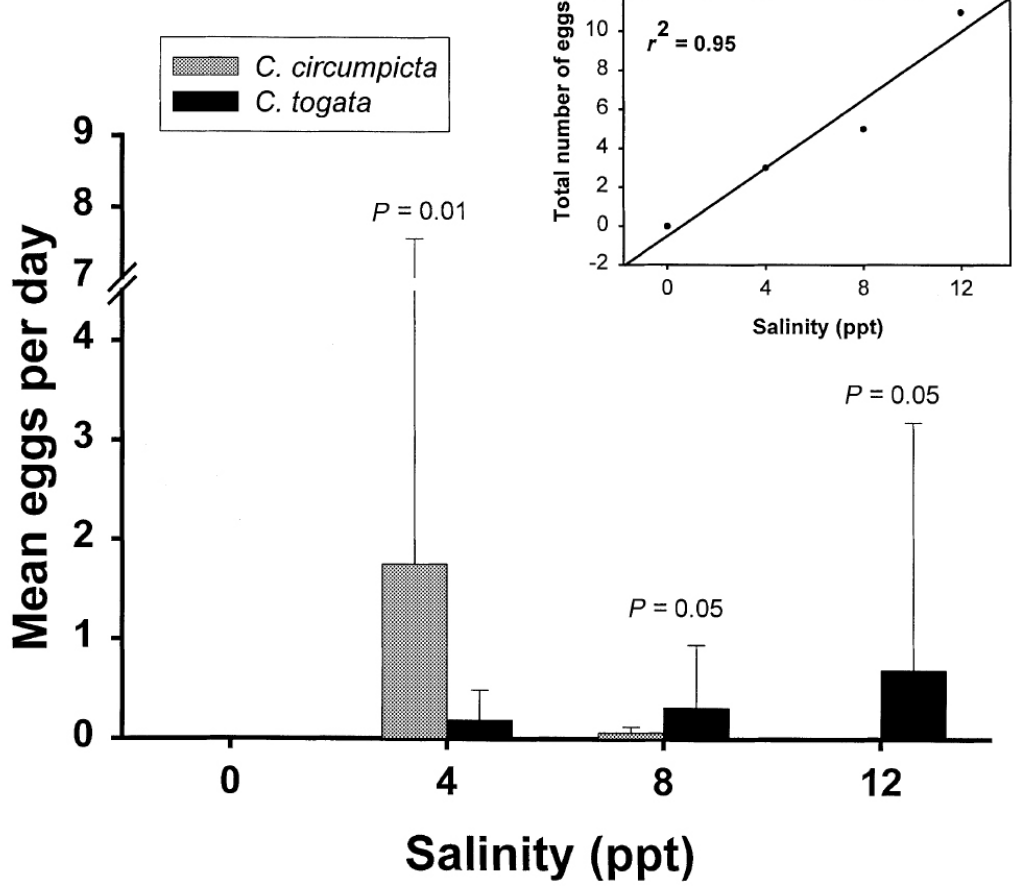

Figure 2. Oviposition by adult Cicindela circumpicta and Cicindela togata as a function of experimental salt concentrations. Bars represent mean number of eggs \pm SE per sampling period $(n=8)$. For each salinity, a Student's $t$-test was performed $(P$-values shown above bar). Inset shows linear regression of total number of $C$. togata eggs per condition vs. salt concentration. Neither species laid any eggs in the 0 salt treatment.

0.05). There also were no significant differences between burrow numbers in any quadrat $[\mathrm{NW}, \mathrm{SW}, \mathrm{NE}$, and SE $\left(\chi^{2}\right.$ goodness of fit, $P>0.05$; Figure $\left.\left.3 b\right)\right]$. There are several possible interpretations for this result. Female oviposition may occur in the shade of the stakes throughout the day. Alternatively, females may cool themselves by seeking the shade of the stake then lay eggs in a narrow time frame near the thermal refuge without consideration for the presence of shade. Lastly, females may select oviposition sites in response to the vertical stimulus of the stake and not select areas based on the presence of shade.

To distinguish among these hypotheses, a second experiment where the number of first instars associated with wire frames with or without screen was conducted. Significantly more new larvae were found in the shaded treatments than in the exposed treatments (Figure 4). The numbers of new burrows increased slowly from the time of placement (July 17) until the conclusion of the experiment (August 10) when there were 53 burrows under shaded treatments and three in exposed treatments. The three burrows found within the open framed areas were found near the vertical wire support, suggesting that females laid eggs in response to the shade cast by the vertical support. As further evidence of the role of shade vs. vertical stimulus, the 53 burrows found in shaded treatments were dispersed randomly in the shade and not concentrated near the support. Thus, it appeared that female tiger beetles (presumably $C$. togata based on salinities) were using shade as an oviposition cue.

The shaded treatments decreased salt flat surface temperatures significantly (mean $\pm \mathrm{SE} 41.7 \pm 0.27^{\circ} \mathrm{C}$ in experimental shade, $48.0 \pm 0.38^{\circ} \mathrm{C}$ on exposed flats; Student's t-test, $P<0.001)$ and were similar $(P>0.05)$ to the shading effect of halophyte plants (shaded soil temperature was $40.3^{\circ} \mathrm{C}$ ). Although soil temperatures were different, soil salinity was unaffected by shading treatments. Salinity was $8.0 \pm 0.38 \mathrm{ppt}$ for shaded soils and $8.0 \pm 0.15$ for exposed soils.

Effects of Shade on Hatching

Because eggs collected in laboratory experiments were placed into areas of the salt flat that were without halophytes and were devoid of existing larval burrows, the possibility that shade would allow larval survival in areas that were previously unusable was considered. Significantly more C. circumpicta and C. togata eggs hatched in shaded treatments than in control treatments. For C. circumpicta, $78 \%$ of eggs hatched in shaded conditions and $22 \%$ hatched in exposed conditions ( $n=9$ per treatment). For $C$. togata, $43 \%$ of eggs in shaded conditions hatched but none hatched in ex- 

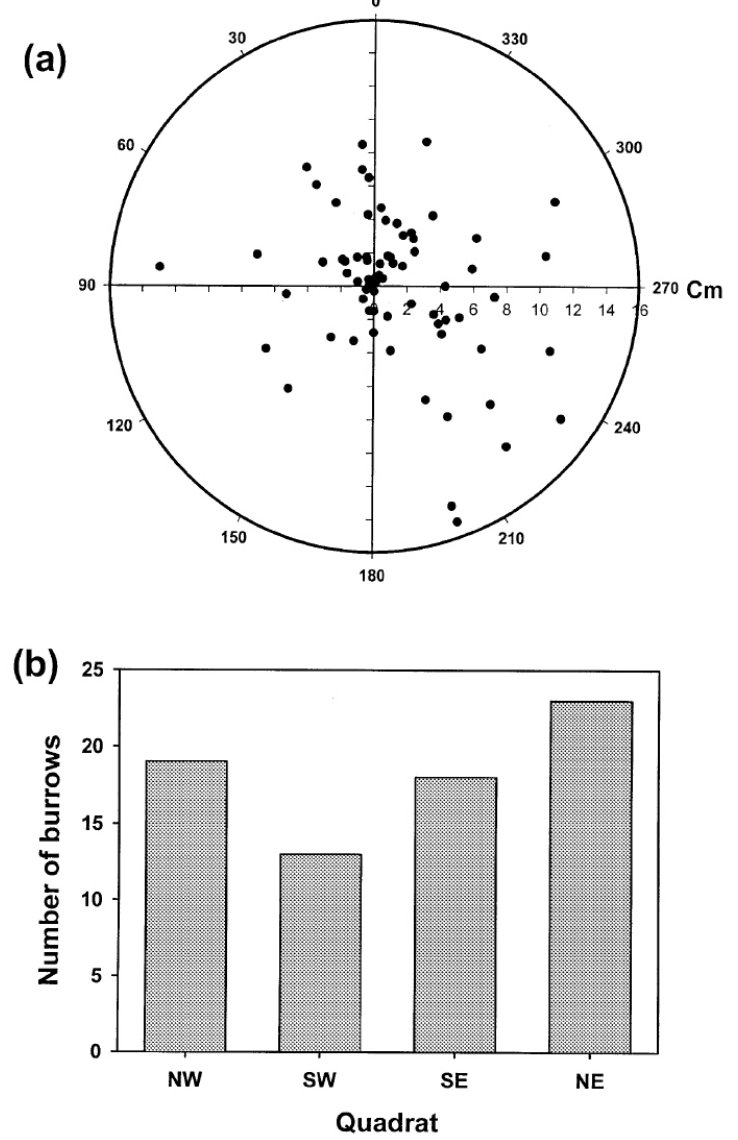

Figure 3. (a) Distance and angle from stake of neonate tiger beetle larvae (presumably Cicindela togata, see Discussion). Each point represents an individual larval burrow $(n=73)$. North $=0$ and $360^{\circ}$, west $=90^{\circ}$, south $=180^{\circ}$, east $=270^{\circ}$. (b) Total number of neonate burrows per quadrat. Quadrats were defined as follows: $\mathrm{NW}=0-90^{\circ}, \mathrm{SW}=$ $91-180^{\circ}, \mathrm{SE}=181-270^{\circ}$, and $\mathrm{NE}=271-360^{\circ}$. No significant directional effects were detected $\left(\chi^{2}\right.$ goodness of fit $\left.P>0.05\right)$.

posed conditions ( $n=7$ per treatment). Despite hatching success, only two C. circumpicta (both in shaded conditions) were maintaining burrows and had grown to second instars by the conclusion of the experiment (August 8).

\section{Discussion}

Because tiger beetle larvae are ambush predators that form (usually) permanent burrows at the site of oviposition, female choice of suitable sites is critical for larval survival. Beyond the need to choose sites where larvae can tolerate abiotic conditions, females must also select sites that will provide access to appropriate prey for larval growth. Because the majority of tiger beetle species and their larvae are restricted to a narrow range of habitats that are relatively devoid of plant cover, interspecific competition among larvae may also influence larval survival and growth rate and should result in strong selection pressure for niche differentiation.

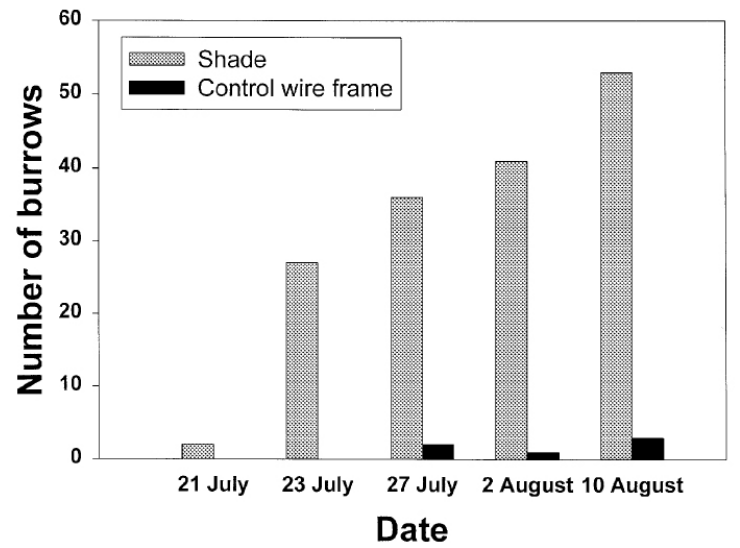

Figure 4. Total number of neonate tiger beetle burrows under artificial shade (gray) and control wire frames (black) vs. sampling date $(n=9$ per treatment per date).

The work reported here provides the first detailed study of ovipositional preferences by sympatric tiger beetle species. It was found that females require saline soils to initiate egglaying behavior, an observation consistent with the habitat specificity of these species (Willis, 1967; Spomer et al., 1997). Although adults of both species are temporally and spatially sympatric, $C$. circumpicta females selected a soil salinity near $4.0 \mathrm{ppt}$ while $C$. togata selected higher salinities. These laboratory findings are supported with field observations of microhabitat segregation between larvae of the two species (Willis, 1967; present study).

Selection of oviposition site may be primarily through chemoreception. Carabid beetles select preferred habitats through associations of habitat-specific volatile chemicals (Evans, 1988). Willis (1967) observed female C. circumpicta and C. togata touching the soil with antennae and sometimes biting the soil prior to excavating oviposition holes. As found by Shelford (1911), females often dig multiple holes prior to laying an egg (Willis, 1967). Because each potential oviposition hole is dug to a depth between 0.5 and $1 \mathrm{~cm}$ and requires $5-10 \mathrm{~min}$ to dig, oviposition is time intensive and may comprise a significant energetic expense. A second mechanism for substrate sampling may be through mechanoreception by the ovipositor itself. Leffler (1979) reported a correlation between ovipositor morphology and substrate composition for Pacific tiger beetles. Species that occur in sandy soils have long thin ovipositors while species occurring in clay have shorter, stouter ovipositors. The ovipositors of $C$. circumpicta and $C$. togata are very similar (Willis, 1967; W. Hoback, pers. obs.) and, thus, probably do not playa role in oviposition site selection based on soil particle size.

In addition to selecting appropriate salinities, adult females select sites behaviorally based on shade. In this series of experiments, the species of larvae was not identified; however, because stakes and artificial 
shade structures were placed away from halophytes and existing burrows and because soil salinity in these areas exceeded $8.5 \mathrm{ppt}$, it is likely that all larvae were C. togata.

Shade may be important for several reasons. Specifically, shade reduces the soil surface temperature and may reduce the risk of death from heat stress and desiccation for eggs and neonate larvae. Shade may also enhance survival after burrows are formed by providing access to significantly more potential prey. Hoback et al. (1999) found that approximately $75 \%$ of total potential prey (excluding adult tiger beetles) were collected on sticky traps placed in the shade of plants. Larval food availability has been considered to be perhaps the most important limiting resource for cicindelid populations (Knisley \& Schultz, 1997) and death from starvation of C. punctulata Olivier was estimated to be 75\% (Mury Meyers, 1983). Although not quantified, survival of newly emerged larvae presumably depends most on early prey capture because firstinstar larvae have the smallest proportional fatty acid reserves (W. Hoback, pers. obs.) of any instar.

This behavioral preference for shade may also explain partially the relatively low number of eggs obtained in laboratory experiments. Alternative explanations for low rates of oviposition in the laboratory may include requirements for other soil characteriztics associated with saline soil, the fact that most adults were collected several weeks postemergence and could have already exhausted the majority of their eggs, or low numbers of eggs may reflect an as yet unreported difference in the biology of salttolerant species. In addition, Drosophila may not provide adequate nutrition for egg development in tiger beetles as seen in some ground beetles (Jorgensen \& Toft, 1997). In laboratory studies, average fecundity for tiger beetles was estimated to be between 10 and 50 per adult for eastern North American species (Shelford, 1908), between 20 and 50 for Arizona species (Knisley \& Schultz, 1997), and up to 310 for a large Oriental species (Hori, 1982).

Summer species of tiger beetles typically emerge with immature gonads and require about 3 weeks of ovarian development prior to egg-laying (Knisley \& Schultz, 1997). The period of oviposition seems to be limited for most species, with the exception of C. japonica (Thunberg) (Hori, 1982). The egg-laying period and oviposition site choices appear to be influenced by abiotic conditions and are especially sensitive to rainfall (Shelford, 1911).

Moist soil is required for oviposition and larval survival of most tiger beetle species (Shelford, 1911; Palmer, 1978; Knisley, 1987). Desiccation of the substrate presumably presents two problems for emerging larvae: larval tiger beetles may die from water loss (Hadley et al., 1989) or they may not be able to excavate the larval burrow and may starve. However, conditions that are too wet may also lead to egg and larval mortality from drowning (Hoback et al., 1998) or potentially from the growth of fungus. As in previous studies, closer examination of species that apparently contradict the principle of competitive exclusion, reveals new information that supports the premise. Niche partitioning by larval habitat appears to explain partially the coexistence of these closely related, co-occurring species. If larval mortality for these species is high, as reported in previous studies (92-98\% mortality; Knisley \& Schultz, 1997), adults may not reach high enough numbers to compete directly. In previous work, however, Hoback et al. (1999) found that the salt marsh habitat has a limited prey base with tiger beetles comprising about $30 \%$ of all collected insects.

Here, niche partitioning through differences in oviposition and corresponding larval habitat was demonstrated. This represents an adaptation that minimizes interspecific larval competition. An interesting question that emerges, particularly for holometabolous insects, is whether niche partitioning can occur only in a single stage or whether such partitioning must occur in both immatures and adults. This question is being explored in companion studies with adult C. circumpicta and C. togata.

Acknowledgements

We thank David Stanley for helpful comments on an earlier version of this manuscript. This work was supported by the Agricultural Research Division, UNL, University of Nebraska Agricultural Experiment Station Project 17-068 and the W. E. Weaver Small Grants Program of the Nebraska Chapter of the Nature Conservancy to W. Hoback. This is manuscript number 12590 and contribution number 1020 from the Department of Entomology, University of NebraskaLincoln.

References

Batschelet, E. (1981). Circular Statistics in Biology. Academic Press, New York.

Broadhead, E. (1958). The psocid fauna of larch trees in northern England: an ecological study of mixed species populations exploiting a common resource. Journal of Animal Ecology 27: 217-263.

Broadhead, E., and A.J. Wapshere (1966). Mesopsocus populations on larch in England: the distribution and dynamics of two closely related co-existing species of Psocoptera sharing the same food source. Ecological Monographs 36: 327-388.

Criddle, N. (1907). Habits of some Manitoba tiger beetles (Cicindelidae). Canadian Entomologist 39: 105-114.

Criddle, N. (1910). Habits of some Manitoba tiger beetles, no. 2 (Cicindelidae). Canadian Entomologist 42: 9-15.

Evans, W.G. (1988). Chemically mediated habitat recognition in shore insects (Coleoptera: Carabidae; Hemiptera: Saldidae). Journal of Chemical Ecology 14: 1,441-1,454.

Gause, G.F. (1934). The Struggle for Existence. Williams \& Wilkins, Baltimore, Maryland.

Hadley, N.F., C.B. Knisley, T.D. Schultz, and D.L. Pearson (1989). Water relations of tiger beetle larvae (Cicindela marutha): correlations with habitat microclimate and burrowing activity. Journal of Arid Environments 19: 189-197. 
Hoback, W.W., L.G. Higley, D.W. Stanley, and M.C. Barnhart (1998). Survival of immersion and anoxia by larval tiger beetles Cicindela togata. American Midland Naturalist 140: 27-33.

Hoback, W.W., T.M. Svatos, S.M. Spomer, and L.G. Higley (1999). Trap color and placement affects estimates of insect family-level abundance and diversity in a Nebraska salt marsh. Entomologia experimentalis et applicata 91: 393-402.

Hori, M. (1982). The biology and population dynamics of the tiger beetle Cicindela japonica (Thunberg). Physiology and Ecology Japan 19: 77-212.

Jorgensen, H.B., and S. Toft (1997). Food preference, diet dependent fecundity and larval development in Harpalus rufipes (Coleoptera: Carabidae). Pedobiologia 41: 307-315.

Knisley, C.B. (1984). Ecological distribution of tiger beetles in Colfax County, New Mexico. Southwestern Naturalist 29: 93-104.

Knisley, C.B. (1987). Habits, food resources and natural enemies of a community of larval Cicindela in southeastern Arizona (Coleoptera: Cicindelidae). Canadian Journal of Zoology 65: 1,1912,000 .

Knisley, C.B., and T.D. Schultz (1997). The biology of tiger beetles and a guide to the species of the south Atlantic states. Virginia Museum of Natural History Special Publication Number 5, Martinsville, Virginia.

Leffler, S.R. (1979). Tiger beetles ofthe Pacific Northwest (Coleoptera: Cicindelidae). PhD dissertation, University of Washington, Seattle, U.S.A.

McClure, M.S., and P.W. Price (1976). Ecotype characteriztics of coexisting Erythroneura leafhoppers (Homoptera: Cicadellidae) on American sycamore. Evolution 56: 1,388-1,397.

Mury Meyers, E.J. (1983). An analysis of survivorship and foraging methods in the larvae of three sympatric species of tiger beetles (Coleoptera: Cicindelidae) occurring in central Pennsylvania. PhD dissertation, Pennsylvania State University, University Park, Pennsylvania.
Palmer, M.K. (1978). Growth rates and survivorship of tiger beetle larvae. Cicindela 10: 49-66. Pearson, D.L. (1988) The biology of tiger beetles. Annual Review of Entomology 33: 123-147.

Pearson, D.L., and S.A. Juliano (1991). Mandible length ratios as a mechanism for co-occurrence: evidence from a world-wide comparison of tiger beetle assemblages (Cicindelidae). Oikos 61: 223-233.

Price, P.W. (1997). Insect Ecology, 3rd edition. Wiley, New York.

Ricklefs, R.E. (1990). Ecology, 3rd edition. W.H. Freeman, New York.

Ross, H.H. (1957). Principles of natural coexistence indicated by leafhopper populations. Evolution 11: 113-129.

Schultz, T.D. (1989). Habitat preferences and seasonal abundances of eight sympatric tiger beetle species of the genus Cicindela (Coleoptera: Cicindelidae) in Bastrop State Park, Texas. Southwestern Naturalist 34: 468-477.

Schultz, T.D., and N.F. Hadley (1987). Microhabitat segregation and physiological differences in co-occurring tiger beetle species, Cicindela oregona and Cicindela tranquebarica. Oecologia 73: 363-370.

Shelford, V.E. (1908). Life histories and larval habits of the tiger beetles (Cicindelidae). Journal of the Linnean Society of London, Zoology 30: 157-184.

Shelford, V.E. (1911). Physiological animal geography. Journal of Morphology 22: 551-618.

Southwood, T.R.E. (1979). Ecological Methods with Particular Reference to the Study of Insect Populations, 2nd edition. Methuen, London.

Spomer, S.M., L.G. Higley, and W.W. Hoback (1997). Nebraska's salt marsh tigers. University of Nebraska State Museum Notes 97: 1-4.

U.S. Soil Conservation Service (1980). Soil Survey of the Counties of Nebraska: Lancaster County.

Willis, H.L. (1967). Bionomics and zoogeography of tiger beetles of saline habitats in the central United States (Coleoptera: Cicindelidae). University of Kansas Science Bulletin 48: 145-313. 